\title{
Review of the Renewable Energy Status and Prospects in Pakistan
}

\author{
Syed Zafar Ilyas ${ }^{1(\mathbb{D})}$, Ather Hassan ${ }^{1 *}:(\mathbb{D})$ Hareem Mufti ${ }^{1}$ (D) \\ ${ }^{1}$ Department of Physics, Allama Iqbal Open University, Islamabad, Pakistan \\ (szilyas@aiou.edu.pk, ather.hassan@aiou.edu.pk, hareem.mufti@aiou.edu.pk) \\ $\$$ Corresponding Author; Phone: +92519057214; Fax: +92519250067, ORCID: 0000-0002-9784-6760 \\ E-mail: ather.hassan@aiou.edu.pk
}

Received: 11.12.2021 Accepted:28.12.2021

\begin{abstract}
The research will discuss and explore the status and prospects of renewable energy sources (solar, wind, and biomass) in Pakistan. The future power demand, as well as the general growth in power consumption, were considered. The findings demonstrated that renewable energy sources like solar, wind, biomass, and hydro are the only remedies to tackle Pakistan's future energy challenges. Moreover, the potential energies of offshore wind, tide waves, ocean terminals, and geothermal need to be investigated and discovered. The geographical location of the region arrests $7 \mathrm{kWh} / \mathrm{m}^{2}$ solar insolation daily, which can produce 25 MJ of energy. In addition, global irradiation on a horizontal surface can generate $2.4 \mathrm{MWh}$ of energy per annum. Similarly, plains and mountain regions can generate 50,000 MW of electric power. Additionally, the importance of renewable energy in graduation and post-graduation programs and public awareness has been addressed. It has been concluded that due to the geographical location, solar energy is the short-term and best solution to deal with the energy crisis in Pakistan.
\end{abstract}

Keywords: - Renewable energy status and future. higher education, public awareness

\section{Introduction}

Global warming, rapid escalating energy demand, and depletion of fossil fuels are the challenging factors of the $21^{\text {st }}$ century [1]. The prevailing scenario attracts scientists and engineers to look for alternate energy resources to fulfill the future energy requirements of the World [2,3]. Renewable energy such as wind, solar, and hydro are being studied extensively in many parts of the world [4-7].

Pakistan is experiencing a catastrophic power breakdown that lasts for 12 hours in cities and 18 hours in rural areas each day and is likely to get worse over time [8]. The country's overall economy is being damaged by the energy deficit. The prolonged power breakdown also affects the industrial sectors, where highcost energy is supplied for production [9]. Pakistan is not selfsufficient in energy production [10]. The country's per capita energy consumption is $3894 \mathrm{kWh}$, while the global average per capita energy is recorded as $17620 \mathrm{kWh}$. The current growth rate is approximately $2 \%$, and by 2050 , it is anticipated to drop to less than $1 \%$. In addition, the population is anticipated to exceed 300 million. In 2020, the population was 210 million, and by 2030, it is expected around 245 million [11,12]. According to Energy Year Book (EYB) for 2018-19, the annual growth rate of primary energy supply was $8.44 \%$ in FY 2017-18 and -2.88 $\%$ in FY 2018-19. Similarly, the annual growth rate of final energy consumption remained at $9.72 \%$ and $0.005 \%$ in FY 2017-18 and FY 2018-19, respectively [11].

According to a recently released report by Global Data, the global distribution transformers market for national energy grids is anticipated to expand at a compound annual growth rate of 1.6 percent, reaching $\$ 14.33$ billion in 2022. Rapid urbanization, industrialization, and the provision of power to rural regions throughout the country contributed to a significant annual compound growth rate (ACGR) of a 10.9 percent rise in power demand from 2005 to 2010 [13]. The power demand in Pakistan has increased from 13,000 to $23835 \mathrm{MW}$ as a consequence of a non-serious attitude toward the construction of new dams, alternative energy, research, and higher education programs in the energy field. Consequently, the supply-demand imbalance is widening day by day [14]. 2020). The other facts which increase the supply-demand gap are:
a). Lack of investment in existing plants
b). Outdated grids distribution system
c). Electricity theft 
d). Line losses

Agriculture, commerce, and other sectors all have a 5.3 percent, 5.86 percent, and 5.32 percent increase in electricity consumer demand, respectively [15].

\subsection{Geographical location}

Pakistan's latitudinal and longitudinal positions are $30^{\circ} 23^{\prime} 21.84^{\prime \prime E}$ and $69^{\circ} 21^{\prime} 11.59^{\prime \prime} \mathrm{E}$, respectively. It spans from the Pamirs to the Arabian Sea, touching the Hindukush Mountains in the north. The country is approximately four times the size of the United Kingdom, with a total area of 796,095 sq $\mathrm{km}$. The region stretches over 1,800 kilometers from Gwadar Bay in the south-eastern corner to the Khunjerab Pass on China's border. It has different landscapes such as a) the western offshoots of the Himalayas, which cover the northern and northwestern parts of the country and whose highest peak, K-2, rises to 8611 meters above sea level; b) the Balochistan plateau; c) the Potohar Plateau and salt range; and d) The Indus plain, the most fertile and densely populated area of the country. It gets its sustenance from the Indus River and its tributaries [16].

Pakistan has a great deal of diversity in terms of climate. Winters in the north and northwestern high mountain ranges are extremely cold, while the summer months of April to September are pleasant. In the summer, the plains of the Indus valley are scorching hot, while the winters are cold and dry. The climate on the southern coastal strip is moderate. The yearly average rainfall in the plains varies from 16 centimeters in northern areas of the lower Indus plain to 120 centimeters in the Himalayan region. Monsoonal rains come late in the summer. Humidity is relatively low due to the rain and wide diurnal temperature variation. The coastal strip is the only place with considerable humidity [17].

Pakistan holds the world's best region for harvesting renewable energy sources like solar, wind, and biomass. Solar, wind, and biomass are the most promising renewable energy sources in Pakistan. The findings demonstrate that solar energy is a more practical, cost-effective, and affordable option for Pakistan than other renewables such as wind energy. The solar energy costs 0.17 US dollars $/ \mathrm{kW}$ and wind energy costs 0.75 US dollars/ $\mathrm{kW}$ due to metrological factors variation during four months of the year. In the remaining eight months, the wind speed is neither feasible nor cost-effective.

\subsection{Electricity}

The installed power generation capacity of the country has reach $37,402 \mathrm{MW}$ in 2020 [18]. However, it fluctuates between 11640 MW in summer and $17523 \mathrm{MW}$ in winter due to weather and seasonal variations. Water reservoir levels increase due to rains, which increase the electricity generation. It is reported that in the last 10 years the consumption of electricity has increased by $10.9 \%$ per year due to rapid urbanization, the extension of electricity to un-electrified rural areas throughout the country. Electricity demand is rising exponentially[19].
A modeled study forecasts net electricity demand to increase from 106 TWh in 2017-18 to 178 TWh by 2029-30, an increase of 72 TWh [20]. Pakistan's energy consumption is continually increasing, resulting in an annual supply-demand imbalance. The other fact involved in increasing the supply-demand gap is the lack of investment in old existing plants, outdated distribution and grids system, electricity theft, and line losses. These factors cause hourly energy losses of $19 \mathrm{Gw}$.

\subsection{Higher Education}

In Pakistan, 226 public and private institutions have been founded, with 20 engineering universities. There are 3224 technical institutes in Pakistan, however, none of them offer degrees in renewable energy resources. The Universities are not playing their role in the development of local industries and projection of today's technology. Universities dedicated to science and technology are placed together in general universities. Students' interest in engineering (civil and electrical) and medicine is higher than in any other subjects, and renewable courses are neglected in all universities except Allama Iqbal Open University, where two subjects regarding renewable energy resources are offered on M.Phil and Ph.D. levels. There is only one renewable energy research group in Pakistan, and the co-author is the director of the group [21].

\subsection{Renewable Energy in Pakistan}

Renewable energy technologies such as solar (solar power plants), wind energy (wind turbines), thermal energy, and even ocean waves have increased the world's electricity generation [22]. Using computer intelligence, people have evaluated the economic benefits of hydro and wind power generation systems $[3,23,24,47]$. In Pakistan, the daily solar insolation is recorded 5 to $7 \mathrm{kWh} / \mathrm{m}^{2} /$ day, which provides 18 to $25 \mathrm{MJ}$ energy/day. Therefore, such insolation is considered best for solar energy in the world [25]. The overview of the renewable energy of Pakistan is provided in the Sub-section.

\subsubsection{Solar Energy}

Pakistan is ideally positioned in the sunny belt of the world. It has lengthy daylight spans each day and strong insolation levels, making it ideal for solar energy technology. The daily mean global irradiation on a horizontal surface in Pakistan ranges from 1900 to $2200 \mathrm{kWh} / \mathrm{m}^{2}$ [26]. This amount of irradiation is equivalent to 1500-3000 sunshine hours and can generate 1.9 2.3 MWh of energy annually.

\subsubsection{Wind Energy}

Wind energy has a great potential in Pakistan's coastal districts (Balochistan and Sindh), which are considered God-gifted wind corridors [27-32]. The mountain areas KPK, Gilgit Baltistan, and Balochistan contain natural ventures for wind energy harvesting. Furthermore, many plain regions in Sindh and Punjab have high wind energy profiles. In these regions, wind energy can generate 50,000MW of electricity. 


\subsubsection{Hydro Energy}

Pakistan's fifth province is located in the country's northwestern region and has a lot of hydroelectric potentials. Microhydropower (MHP) with a capacity of up to $300 \mathrm{~kW}$ has been installed in various regions. In the north, the potential of perpetual waterfalls is estimated to be $500 \mathrm{MW}$. The people living in remote areas will get a great benefit from these sources. The 300 waterfalls in Punjab's canal network can generate 350 MW of electricity. The power plant with a capacity of $3 \mathrm{MW}$ has been constructed on 228 "run of river type" sites in Khyber Parkton Khawa (KPK). The electricity generated by such power plants is used for lighting, and other domestic purposes such as flour mills, thrashing of maize, and cotton ginning. Punjab province has enough financial resources, but no real progress has been seen in small or large hydropower plants. Azad Jammu and Kashmir are endowed with abundant hydel potential, but they also didn't show real progress. Despite this, they have just begun a 36MW project against a 5,329 MW target. The Kalabagh dam project was sanctioned in 1960 and was supposed to begin in 1964 or 1967, but it has yet to begin owing to political concerns, as have other projects.

\subsubsection{Tide, wave, and ocean thermal energy}

From Sindh to Balochistan, Pakistan's coastline runs over 1100 kilometers. The coastal population lives near the water. The greatest impediment to discovering Pakistan's potential is a lack of funds. In addition, the potential of tidal energy, wave energy, and energy from ocean thermal energy converters(OTEC) must be investigated in coastal areas. The maximum depth of the Arabian sea is approximately $4662 \mathrm{~m}$, therefore, the feasibility of OTEC is expected.

\subsubsection{Geothermal Energy}

Three studies were conducted in Islamabad, however, none of them were effective due to the soil issue [26,33]. More research studies are needed to fully explore the geothermal energy potential [34].

\subsubsection{Biomass Energy}

The public has shown keen interest in biomass energy, which can be verified by their progress during the last 15 years. Almost three villages in Punjab Province are now reliant on Biomass, and this ingenuity is being passed on to the other community $[28,35]$. In Pakistan, the production of biomass has begun. However, before launching these Projects, the negative impacts on humans, agriculture, and the environment are not focused on. Environmental studies and public awareness of the negative consequences of biomass must be addressed. In Pakistan, there is a lot of potential for biofuels. A little study material is available regarding biofuels, and no significant production has started. In the coming days, biofuel is targeted as the future energy.

\subsection{Renewable Energy Trend in Pakistan:}

The public's interest in renewable energy has reportedly been increased during the last five years because the government gives incentives in the renewable energy industry. The government is committed to the country's continuing growth in the energy sector. Higher Education Commission (HEC), Pakistan Science Foundation (FSC), and Ministry of Sciences and Technology (MoST) have started funding alternate energy research projects. The government also encouraged other countries to collaborate on studies in the field of renewable energy for power generation. Scientists, engineers, and researchers have declared Pakistan the best location for solar and wind energy harvesting. According to the research [36-41], commercial solar projects on a big scale are possible in most of the region. Before committing to the project, however, incidence angle, air mass, temperature, cell temperature, humidity, pollution, and dust must all be evaluated. One solar energy plant of $150 \mathrm{MW}$ in Bahawalpur and one wind energy project of 50 MW in Nandi Pur, Sindh, have been installed by the Punjab government. The project will beneficial for reducing carbon dioxide and the environment.

This review looks at the possibilities, status, and availability of alternative energy in Pakistan for the public and private sectors. In addition, possible alternative energy resources are reevaluated. The main objective of the study is to inspire the government to do more efforts for exploring this sector, and to educate the masses about fossil fuels alternatives.

\section{Experimental Methodology}

A time slot of (1992 to 2013) was selected as a study period. Total as well as sector-wise electricity consumption, conventional energy such as hydro, fossil fuels, and nuclear energy resources, and solar insolation data were provided by the Pakistan Bureau of Statistics. The provided data was first tabulated and then statistically analyzed. The "origin" module was used to plot the number of consumers against stipulated time i.e., 1992 to 2013. The energy resources were analyzed for domestic, industrial, government, and agriculture sectors, and results were presented by pi-chart. The sector was energy consumptions and different energy resources were also presented by pi-chart.

\section{Results and Discussion}

The number of electricity users is depicted in Figure 1. Electricity shortages are projected in the future, based on existing trends. The energy demand is projected to achieve a level of 96.49 million TOE's by 2022 due to urbanization, industrialization, and domestic demand due to population increase. The per capita consumption stands at $3894 \mathrm{kWh}$ as compared to the world average of $17620 \mathrm{kWh}$ per capita, which shows that Pakistan's per capita consumption is less than onefifth of the world average and about 5\% of OECD countries consumption [42]. 


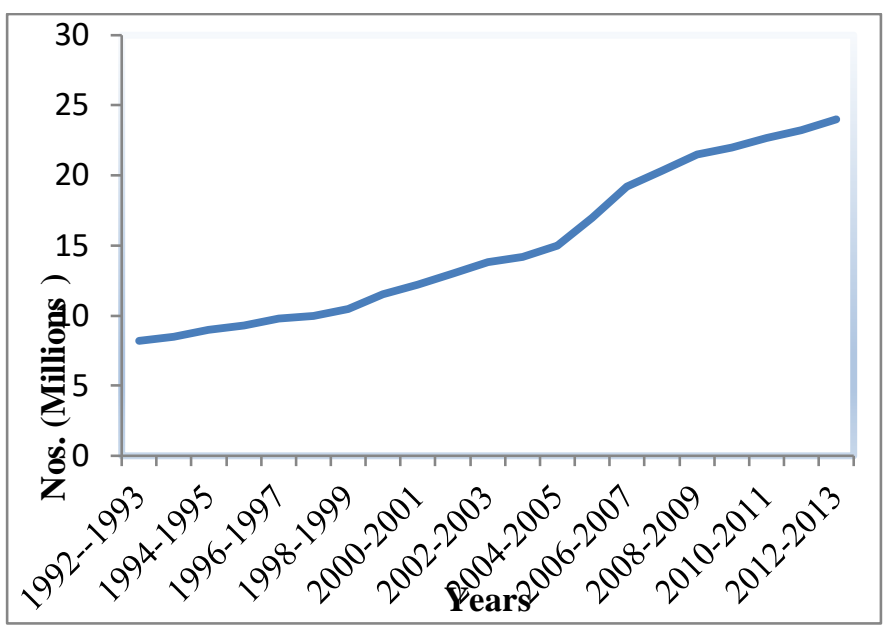

Figure 1 Electricity consumer's growth in numbers

The sector-wise consumption is depicted in Fig. 2. The annual increase in energy demand is $8 \%$ to $12 \%$.

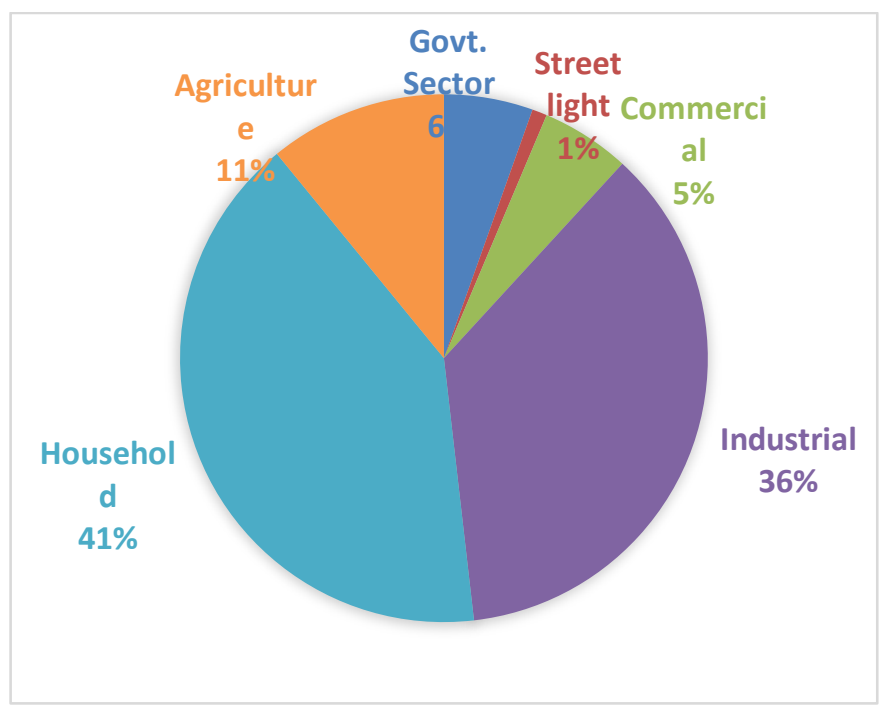

Figure 2 Sector-wise energy consumption in Pakistan (20132014)

In Pakistan, most of the primary energy resources are oil and natural gas. Hydropower is the country's main source of renewable energy, but the share of wind and solar energy is slowly increasing. The total renewable energy production has crossed the limit of 39934 kilo TOE. More than 40 million people are still deprived of electricity, and half of the population does not avail of clean cooking facilities [43]. Figure 3 demonstrates that fossil fuels account for $87.7 \%$ of overall energy demand.

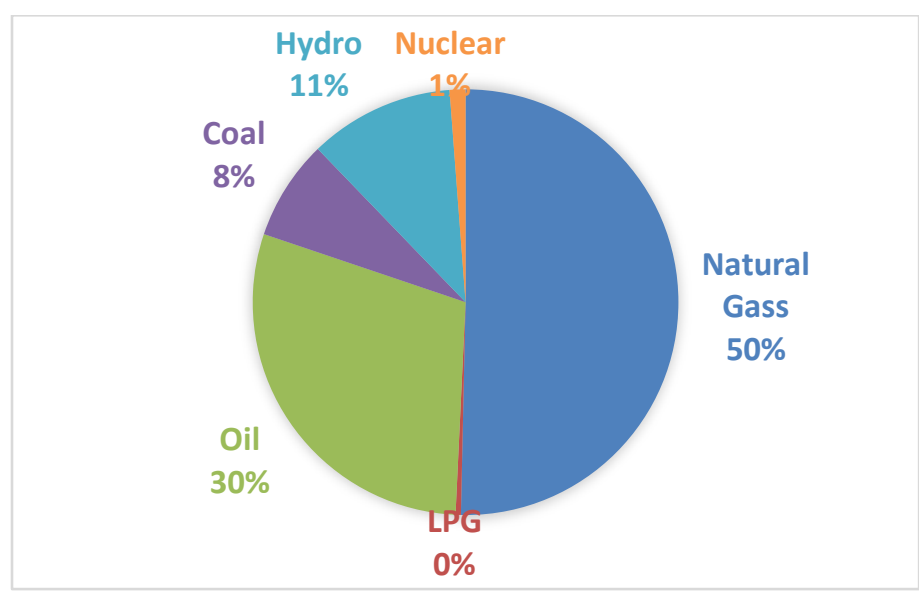

Figure 3 Use of different energy resources in Pakistan

Consequently, looking for clean and alternative energy sources to satisfy future energy demand is strongly advised. Alternative energy resources such as solar, biomass, and wind, which are environmentally benign and locally available, are chosen as the three most potential candidates for power generations.

Based on solar radiation intensity, Pakistan is divided into four zones. The daily annual average mean radiations are given in Table 1.

Table 1 Annual average means daily solar radiation in Pakistan

\begin{tabular}{|c|c|c|c|}
\hline $\begin{array}{l}\text { S. } \\
\text { No. }\end{array}$ & Provence & $\begin{array}{l}\text { Solar } \\
\text { Radiation } \\
\mathrm{kWh} / \mathrm{m}^{2}\end{array}$ & Zone \\
\hline 1 & Balochistan & $5.9-6.2$ & Zone - I \\
\hline \multirow[t]{2}{*}{2} & Sindh & $5.5-5.8$ & \multirow[t]{3}{*}{ Zone - II } \\
\hline & $\begin{array}{l}\text { Khaber Pakhtoon } \\
\text { Khawa (KPK) }\end{array}$ & $5.5-5.8$ & \\
\hline 3 & Southern Punjab & $5.5-5.8$ & \\
\hline 4 & Central Punjab & $5.1-5.4$ & \multirow[t]{2}{*}{ Zone - III } \\
\hline 5 & Coastal Belt of Sindh & $5.1-5.4$ & \\
\hline 6 & Gilgit Baltistan & $4.7-5.0$ & \multirow[t]{2}{*}{ Zone - IV } \\
\hline 7 & Jammu \& Kashmir & $4.7-5.0$ & \\
\hline
\end{tabular}

The Balochistan province is rich in solar energy as shown in Table - 1. The annual mean sunshine duration in Balochistan is 8 to 8.5 hours/day; these values are considered the highest in the world. The given data shows that it is an ideal condition for PV and other solar energy applications, which also help in improving the socio-economic conditions, life stander of the people living in rural areas, and reduction in the poverty level of the country. 
The scientist and researchers have given their recommendations that the available solar energy in Pakistan has played a role to provide sufficient electricity to meet the domestic and industrial electricity requirements $[44,46]$. The weather and climate ofl. Pakistan are in favor of PV use [46]. Solar PV technology may be used anywhere in the country. Solar PV efficiency would be reduced in some regions, such as those with high air temperatures, desert environments, and dust pollution. In urban areas, solar technology is utilized for telephone exchanges,2. emergency telephones on the highway, vaccine refrigeration, and hospital medications. Other applications include solar water pumps for drinking purposes, family parks, and streetlights.3. Recently, the construction of a $1500 \mathrm{MW}$ solar thermal plant has been scheduled in Bahawalpur city of the Punjab province. The4. solar thermal plant reliability and efficiency depend on geographical location (latitude, longitude, and solar intensity), weather and climatic factors (temperature, wind, precipitation,5. humidity, rain, snow, etc.) environmental conditions (dust, pollution, etc), and the PV type used. Figure 4 depicts future of the renewable energy use in Pakistan.

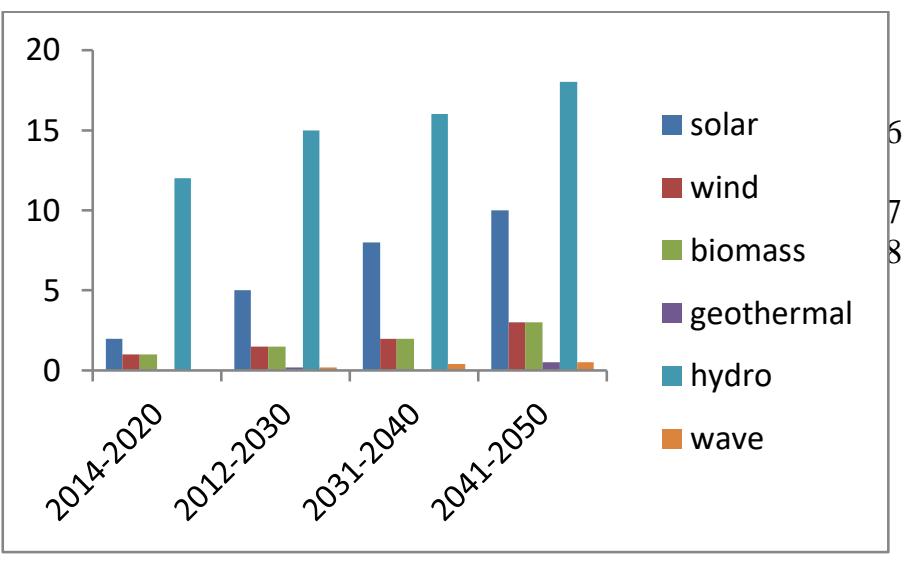

Figure 4 Future of renewable energy in Pakistan

One of the possible solutions is to bridge the gap between supply and demand by increasing power production capacity. In the long term, power generation can be enhanced by hydel and thermal power plants. However, in the short term, renewable energy is the only remedy for present and future energy cries.

The other way is to reduce power consumption by adopting efficient means of electricity usage at the consumer level.

\section{Conclusions and Recommendations}

In Pakistan, the daily solar insolation is recorded 5 to 7 $\mathrm{kWh} / \mathrm{m}^{2} /$ day, which provides 18 to $25 \mathrm{MJ}$ energy/day. Therefore, such insolation is considered best for solar energy in the world. The daily mean global irradiation on a horizontal surface in Pakistan ranges from 1900 to $2200 \mathrm{kWh} / \mathrm{m}^{2}$. This amount of irradiation is equivalent to $1500-3000$ sunshine hours and can generate 1.9 to $2.3 \mathrm{MWh}$ of energy annually. The highlands of KPK, Gilgit Baltistan, and Balochistan provide wind corridors for wind energy harvesting. Furthermore, many plain regions in Sindh and Punjab have a high class of wind profile. In these regions, wind energy can generate $50,000 \mathrm{MW}$ of electricity.

In addition, the potential of tidal energy, wave energy, and energy from ocean thermal energy converters (OTEC) must be investigated in coastal areas. The maximum depth of the Arabian sea is approximately $4662 \mathrm{~m}$, therefore, the feasibility of OTEC is expected.

Support and incentives for implementing renewable pilot projects, especially for individuals living in rural areas without access to grid electricity.

The government should invest in research regarding renewable energy and how it could be used in Pakistan.

Solar thermal collectors and hybrids natural gas geezers for hot water already installed in major cities require government assistance for maintenance.

Renewable energy certification for short-term, graduate, and post-graduate students will produce manpower and will advocate the use of renewable energy. It would be beneficial to encourage and support energy-related research initiatives at the M.Phil/M.Sc and Ph.D. levels. It is necessary to create standards and criteria for the accreditation of standard, academic programs in many academic fields.

5. Insensitive and funds should be provided by the government for installation of Solar System.

7. Public awareness programs should be supported in this regard.

8. The industry needs to be established to meet the future energy crises.

\section{Acknowledgments}

The authors are thankful to the Hydrocarbon Development Institute of Pakistan for providing related data.

\section{Funding}

N/A

\section{Availability of data and materials}

All data and material are available in this paper, so there is no other data to present.

\section{Authors' contributions}

SZ conceived the study, collected the data, and wrote the first draft of the manuscript. AH and HM review the article and made suggestions to the manuscript. All authors read and approved the final manuscript.

\section{Ethics approval and consent to participate}

The authors declared that no human activities are involved.

\section{Consent for publication}

This paper does not include any human in any form (including any individual details, images, or videos). 


\section{Competing interests}

The authors declare that they have no competing interests.

\section{References}

[1]Y. Guan, L. Hongwei, J. Yelin, T. Peipei, Q. Lihua, P. Petri, and Janne Heiskanen, "Changes in global climate heterogeneity under the 21st century global warming." Ecological Indicators 130 (2021): 108075.

[2] P. Minh, and D. Presenter, "DRY REFORMING OF METHANE OVER NICKEL-BASED CATALYSTS FOR SYNGAS PRODUCTION BR DE VASCONCELOS, D. PHAM MINH, P. SHARROCK, A. NZIHOU Mines Albi, CNRS, Centre RAPSODEE, Univ. Toulouse, Campus Jarlard, F-81013 Albi Cedex 09, France Climate changes caused by greenhouse gases emissions, especially $\mathrm{CO} 2$, have driven scientists to develop technologies for $\mathrm{CO} 2$ utilization. Moreover, increases in energy demand and depletion of carbon-based resources have shown the need of substitution of fossil fuels for ...." CEP (2021).

[3] H. Gilani, Azad, and S. Hosseinzadeh, "Techno-economic comparison of compound parabolic collector and flat plate collector in solar water heating systems in the northern hemisphere." Appl. Therm. Eng. (2021): 116756.

[4] S. Hoseinzadeh, iamak, G. H. Mohammad, and H. Stephan, "Application of hybrid systems in solution of low power generation at hot seasons for micro hydro systems." Renewable Energy 160 (2020): 323-332.

[5] M. Makkiabadi, S. Hoseinzadeh, S. M. Mohammadi, S. N. Arabi, S. Bayati, U. Jafaraghaei, S. M. Mirkiai, and M. El Haj Assad, "Energy Feasibility of Hybrid PV/Wind Systems with Electricity Generation Assessment under Iran Environment." Applied Solar Energy 56, no. 6 (2020): 517 525.

[6] A. Sohani, M. H. Shahverdian, H. Sayyaadi, S. Hoseinzadeh, S. Memon, G. Piras, and D. A. Garcia, "Energy and Exergy Analyses on Seasonal Comparative Evaluation of Water Flow Cooling for Improving the Performance of Monocrystalline PV Module in Hot-Arid Climate." Sustainability 13, no. 11 (2021): 6084.

[7] H. K. Sahebi, S. Hoseinzadeh, H. Ghadamian, M. H. Ghasemi, F. Esmaeilion, and D.A. Garcia, "TechnoEconomic Analysis and New Design of a Photovoltaic Power Plant by a Direct Radiation Amplification System." Sustainability 13, no. 20 (2021): 11493.

[8] A. R. Abbasi, and P. Rajpar, "PREVENTION OF PRODUCTION LOSSES IN PAKISTANI POWER GENCOs DUE TO OPERATOR ERRORS-A QUALITATIVE ASSESSMENT." Journal of Business Strategies 15, no. 1 (2021): 59-82.

[9] T. Aized, S. M. S. Rehman, and M. Sumair, "Pakistan energy situation, policy, and issues." In Recent Advances in
Renewable Energy Technologies, pp. 387-428. Academic Press, 2021.

[10] S. Elmassah, "Socioeconomic Determinants of Renewable Energy Production in Emerging and Developed Countries." (2021).

[11] A. Mahmood, X. Wang, A. N. Shahzad, S. Fiaz, H. Ali, M. Naqve, M. M. Javaid, S. Mumtaz, M. Naseer, and R. Dong, "Perspectives on Bioenergy Feedstock Development in Pakistan: Challenges and Opportunities." Sustainability 13, no. 15 (2021): 8438.

[12] https://worldpopulationreview.com/countries/pakistanpopulation" World Population Review" . (last accessed on $13 / 10 / 2021)$.

[13] https://www.power-technology.com/comment/smartgrid/ "Mid Term Development Framework (2005-10), Planning Commission, Islamabad Government of Pakistan. (2010). Mid Term Development Framework (2005-10), Planning Commission, Islamabad " (last accessed on 13/10/2021).

[14] M. Irfan, Z. Y. Zhao, M. K. Panjwani, F. H. Mangi, H. Li, A. Jan, M. Ahmad, and A. Rehman, "Assessing the energy dynamics of Pakistan: prospects of biomass energy" Energy Reports 6 (2020): 80-93.

[15] Hydrocarbon Development Institute of Pakistan. "Pakistan Energy Year Book". (2011).

[16] F. K. Khan. A geography of Pakistan: environment, people and economy. Oxford University Press, (1991).

[17] https://www.pakistanstudiesaips.org/pakistan/geography, The American Institute of Pakistan Studies. (last accessed on 13/10/2021).

[18] https://www.finance.gov.pk/survey/chapter_20/PES 2019 20.pdf Pakistan Economic Survey. Economic Advisor's Wing, Ministry of Finance. (last accessed on 13/10/2021).

[19] A. Rehman, and Z. Deyuan. "Pakistan's energy scenario: a forecast of commercial energy consumption and supply from different sources through 2030." Energy, sustainability and society 8, no. 1 (2018): 1-5.

[20] http://ieefa.org/wp-content/uploads/2018/11/PakistansPower-Future_December-2018.pdf Pakistan's Power Future. (last accessed on 13/10/2021).

[21] https://hec.gov.pk/english/universities/pages/recognised.as px\#k=Higher Education Commission, Pakistan. (last accessed on 13/10/2021).

[22] M. Makkiabadi, S. Hoseinzadeh, A. Taghavirashidizadeh, M. Soleimaninezhad, M. Kamyabi, H. Hajabdollahi, M. M. Nezhad, and G. Piras, "Performance Evaluation of Solar Power Plants: A Review and a Case Study." Processes 9, no. 12 (2021): 2253. 
[23] N. Kefif, B. Melzi, M. Hashemian, M. E. H. Assad, and S. Hoseinzadeh, "Feasibility and optimal operation of micro energy hybrid system (hydro/wind) in the rural valley region." International Journal of Low-Carbon Technologies (2021).

[24] M. Yeghikian, A. Ahmadi, R. Dashti, F. Esmaeilion, A. Mahmoudan, S. Hoseinzadeh, and D. A. Garcia, "Wind Farm Layout Optimization with Different Hub Heights in Manjil Wind Farm Using Particle Swarm Optimization." Applied Sciences 11, no. 20 (2021): 9746.

[25] S. Z. Ilyas, S. M. Nasir, and T. Badshah, " Wind and Solar Energy in Quetta, Pakistan, Research Journal of University of Balochistan, Quetta, Pakistan." Research Journal of University of Balochistan (1), 178-180. (2005).

[26] Z. R. Tahir, and M. Asim, "Surface measured solar radiation data and solar energy resource assessment of Pakistan: A review." Renewable and Sustainable Energy Reviews 81 (2018): 2839-2861.

[27] S. Z. Ilyas, S. M. Nasir, and T. Badshah, " The Theoretical Analysis for A Flat Plate Collector." Journal of Applied and Emerging Science, BUIT \& IMS, Quetta, Balochistan 1(1),198-208. (2004).

[28] S. Z. Ilyas, " Estimation and Comparison of Diffuse Solar Radiation Over Sindh and Punjab, Pakistan," Science International Journal, Lahore (2007).

[29] S. Z. Ilyas, and S. Kakac, "The wind potential in coastal areas of Balochistan, Pakistan." American-Eurasian journal of scientific research 1, no. 1 (2006): 52-54.

[30] S. M. Nasir, and S. M. Raza. "Wind and solar energy in Pakistan," Energy 18, no. 4 (1993): 397-399.

[31] S. M. Nasir, S. M. Raza, and I. A. Raja, "Distribution of wind power resource over Pakistan." Renewable energy 2, no. 4-5 (1992): 411-420.

[32] T. Yusaf, S. Goh, and J. A. Borserio, "Potential of renewable energy alternatives in Australia." Renewable and sustainable energy reviews 15, no. 5 (2011): 2214-2221.

[33] N. A. Zaigham, and Z. A. Nayyar, "Renewable hot dry rock geothermal energy source and its potential in Pakistan." Renewable and Sustainable Energy Reviews 14, no. 3 (2010): 1124-1129.

[34] N. A. Zaigham, Z. A. Nayyar, and N. Hisamuddin, "Review of geothermal energy resources in Pakistan." Renewable and Sustainable Energy Reviews 13, no. 1 (2009): 223-232.
[35] U. K. Mirza, N. Ahmad, and T. Majeed, "An overview of biomass energy utilization in Pakistan." Renewable and Sustainable Energy Reviews 12, no. 7 (2008): 1988-1996.

[36] S. Z. Ilyas, S. M. Nasir, and S. M. Raza, "The Estimate of Global and Diffuse Radiation at Quetta, Pakistan." In Renewable Energy, Technology and the Environment, pp. 2710-2715. Pergamon, 1992.

[37] S. Z. Ilyas, M. Anwar, and S. M. Nasir, "Cumulative frequency distribution of solar insolation at Quetta, Pakistan." Renewable energy 20, no. 1 (2000): 83-86.

[38] S. Z. Ilyas, " Estimation of Diffuse Solar radiation on Horizontal Surface at Quetta, Pakistan." Journal of American-Eurasian Journal of scientific research, 1(2), (2006): 131-134.

[39] S. Z. Ilyas, " A Comparison and Estimation of Diffuse Solar Radiation Over Punjab, Pakistan." American Journal of Applied Sciences

[40] S. Z. Ilyas, S. M. Nasir, and S. Kakae, "Estimation and comparison of diffuse solar radiation over Pakistan." International Scientific Journal of Alternative energy and Ecology, ISJAEE 47, no. 3 (2007): 109-111.

[41] K. H. Solangi, M. R. Islam, S. Rahman, N. A. Rahim, and H. Fayaz. "A review on global solar energy policy." Renewable and sustainable energy reviews 15, no. 4 (2011): 2149-2163.

[42] http://www.pip.org.pk/newsupdates/PEO\%20200708\%20to\%202021-22.pdf Pakistan energy outlook. (last accessed on 13/10/2021).

[43] https://www.iea.org/countries/pakistanInternational Energy Agency (2020) Data and statistics , (last accessed on 13/10/2021).

[44] S. Z. Ilyas, S. M. Nasir, and T. Badshah. "Frequency distribution of wind speed of Quetta, Pakistan." J. of research (Science). Bahauddin Zakariya University, Multan, Pakistan 15, no. 4 (2004): 391-394.

[45] S. M. Nasir, and S. Z. Ilyas, " Wind as an Alternate Source of Energy." Research Journal of University of Balochistan, Quetta, Pakistan, no. 3(3) (2004): 391-394.

[46] S. Z. Ilyas, Utilizing Forest Biomass for Energy in Pakistan: Lessons Learned." Research Journal of University of Balochistan, Quetta, Pakistan (2007).

[47] E. R. A Larico, "Wind Energy Potential by the Weibull Distribution at High-Altitude Peruvian Highlands." International Journal of Smart Grid-ijSmartGrid 5, no. 3 (2021): 113-120. 